\title{
Cancer and hypertension: Debating the clinical link through the $\mathrm{Ca}^{2+} / \mathrm{cAMP}$ signaling
}

\author{
Leandro Bueno Bergantin* \\ Department of Pharmacology - Universidade Federal de São Paulo - Escola Paulista de Medicina, Laboratory of Autonomic and Cardiovascular Pharmacology - 55 \\ 11 5576-4973, Rua Pedro de Toledo, 669 - Vila Clementino, São Paulo - SP, Brazil
}

\begin{abstract}
The incidence of cancer and hypertension is dramatically increasing in worldwide population, costing millions and millions from governments into expenditures related to the medical health systems. Interestingly, hypertension has been clinically linked to an increased risk for developing cancer. However, the mechanisms involved in this possible link are still under intensive debate. In addition, a $\mathrm{Ca}^{2+}$ homeostasis dysregulation has been intensively debated as an issue involved in both cancer and hypertension. Furthermore, calcium $\left(\mathrm{Ca}^{2+}\right)$ channel blockers (CCBs), prescribed for treating hypertension, have been showing anti-cancer effects beyond their property of reducing blood pressure. A debated mechanism of action could rest in the fact that $\mathrm{CCB}$ may maintain, or restore, the $\mathrm{Ca}^{2+}$ homeostasis. Our discovery entitled "calcium paradox" due to the $\mathrm{Ca}^{2+} / \mathrm{cAMP}$ signaling may put some new light in this arena! Then, in this short communication, I have debated the possible involvement of the $\mathrm{Ca}^{2+} / \mathrm{cAMP}$ signaling in the anti-cancer effects of $\mathrm{CCBs}$, including a role of the $\mathrm{Ca}^{2+} / \mathrm{cAMP}$ signaling in the clinical link between hypertension and higher risk for the development of cancer.
\end{abstract}

\section{Introduction}

Cancer and hypertension have become a problematic topic for medical health systems around the world, then costing millions and millions from governments worldwide. Interestingly, hypertension has been associated with a higher risk for developing cancer [1]. Then, debating this clinical link might improve our understanding of the risk factors involved in developing cancer [1]. Indeed, an imbalance of intracellular $\mathrm{Ca}^{2+}$ homeostasis (e.g. intracellular $\mathrm{Ca}^{2+}$ excess) is now being intensively debated as an issue involved in cancer progression, then contributing to the pathogenesis of cancer [2-6].

In addition, and in accordance with the concept described above, calcium $\left(\mathrm{Ca}^{2+}\right)$ channel blockers (CCBs), medicines typically prescribed for treating hypertension, have been demonstrating anti-cancer effects [6-8]. A possible mechanism of action could rest in the fact that these pharmaceuticals may restore the dysregulation of $\mathrm{Ca}^{2+}$ homeostasis [9-13]. Furthermore, the phenomenon entitled as 'calcium paradox', which has been elucidated by us in 2013, has also been associated with the CCBs [14]. In fact, this 'paradox' effect consists in CCBs paradoxically enhancing the release of neurotransmitters (a 'paradox' because intracellular $\mathrm{Ca}^{2+}$ concentration is being decreased by these medicines), very often when these medicines have been used in low doses/concentrations. The reports which describe this 'paradox' have included cellular models as adrenal chromaffin cells, isolated organ bath experiments such as vas deferens, strips of arteries, and most importantly clinical data. Our pioneer study which associates the involvement of the $\mathrm{Ca}^{2+} / \mathrm{cAMP}$ signalling in this 'paradox' has shown to be very significant, considering the broadly use of CCBs as antihypertensive medicines. Then, in this short communication, I have discussed the possible involvement of the $\mathrm{Ca}^{2+} / \mathrm{cAMP}$ signalling in the anti-cancer effects of CCBs, including the role of the $\mathrm{Ca}^{2+} / \mathrm{cAMP}$ signalling in the clinical link between hypertension and higher risk for the development of cancer.
Hypertension and higher risk for the development of cancer, and anti-cancer effects of CCBs

A clinical link between hypertension and a higher risk for the development of cancer has been reported by epidemiological and clinical studies [1,15-17]. However, this clinical link is not fully elucidated, and has been intensively debated. For instance, the Metabolic Syndrome and Cancer Project includes 7 population-based cohorts from Norway, Austria, and Sweden. Briefly, the aim of the Metabolic Syndrome and Cancer Project was to examine the relationship between metabolic factors and cancer risk. Patients in Metabolic Syndrome and Cancer Project cohorts participated in health examination(s) between 1972 and 2005. As main results, a significant positive association per $10-\mathrm{mmHg}$ increment was shown for cancers risk of the oropharynx, rectum, pancreas, lung, prostate, bladder, and kidney [15]. In addition, positive associations per $10-\mathrm{mmHg}$ increments in women were found for cancer risk of the pancreas, breast, corpus uteri, and malignant melanoma. A positive association was also found for esophagus cancer in men and women [15]. In fact, cancer risk has increased linearly by increasing blood pressure levels $[1,15]$. Among men, a risk of cancer incidence or mortality, at age 50 years, was $1 \%$ to $2 \%$ points higher with hypertensive systolic or diastolic blood pressures, compared with normotensive men $[1,15]$.

Furthermore, hypertension has been recognized as a risk factor for cancer in observational reports from renal cell carcinoma [16,17]. A

${ }^{\star}$ Correspondence to: Leandro Bueno Bergantin, Department of Pharmacology Universidade Federal de São Paulo - Escola Paulista de Medicina, Laboratory of Autonomic and Cardiovascular Pharmacology - 5511 5576-4973, Rua Pedro de Toledo, 669 - Vila Clementino, São Paulo - SP, Brazil

Key words: cancer, hypertension, $\mathrm{Ca}^{2+} / \mathrm{cAMP}$ signaling

Received: June 22, 2018; Accepted: June 27, 2018; Published: June 30, 2018 
meta-analysis, based on 18 studies, showed a 1.6-fold increase in the risk of renal cell carcinoma in participants with hypertension [17]. Then, abnormal blood pressure might be an issue for cancer risk; nonetheless this association between high blood pressure and cancer risk may exist combined with other factors, such as central obesity [15]. In addition, CCBs, antihypertensive medicines which reduce the influx of $\mathrm{Ca}^{2+}$ into the cells, have been demonstrating anti-cancer effects [6-8]. Then, how could $\mathrm{Ca}^{2+} / \mathrm{cAMP}$ signaling help to explain this effect, including the association between hypertension and higher risk for cancer?

\section{Hypertension and cancer: the relevance of the $\mathrm{Ca}^{2+} / \mathrm{cAMP}$ signaling}

Considered as vital cellular processes for mammalians, the $\mathrm{Ca}^{2+} /$ cAMP signaling are assumed to virtually exist in almost all mammalian cells, controlled by adenylyl cyclases (ACs), phosphodiesterases (PDEs), $\mathrm{Ca}^{2+}$ channels and so on [18-25] (Figure 1).

In this arena, endoplasmic reticulum (ER) $\mathrm{Ca}^{2+}$ channels have particularly been a vanguard for the field, such as ryanodine receptors (RyR) [18-25]. Through our studies, we have recognized that the $\mathrm{Ca}^{2+} /$ cAMP signaling performance an essential role in: controlling the neurotransmitter release from neurons, and neuroendocrine cells, including modulating the neuronal death [18-21], and in the development of cancer [9-13].

For instance, hypertension has been classically correlated to a sympathetic hyperactivity: reports from Miranda, et al. [26-28] confirmed this idea by observing pronounced differences in the kinetics of catecholamine release from spontaneously hypertensive rats (SHRs), comparing with normotensives. Such differences could be debated on the basis of different mechanisms of $\mathrm{Ca}^{2+}$ signaling. The authors [2628 ] concluded that dysregulations of intracellular $\mathrm{Ca}^{2+}$ signaling could elucidate the greater catecholamine release responses observed in SHRs, compared with normotensive rats.

In addition, $\mathrm{Ca}^{2+}$ dysregulations, such as L-type $\mathrm{Ca}^{2+}$ channels up-regulations, have also been implicated in the development,

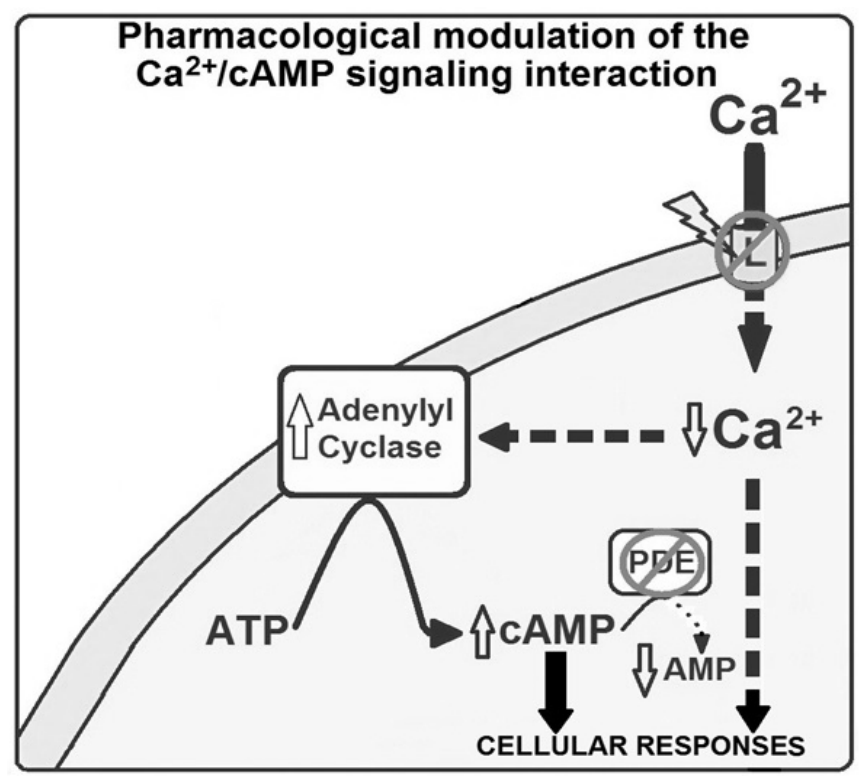

Figure 1. Cellular responses induced by the pharmacological modulation of the $\mathrm{Ca}^{2+} / \mathrm{cAMP}$ signalling pathways. Briefly, the reduction of $\mathrm{Ca}^{2+}$ influx through L-type $\mathrm{Ca}^{2+}$ channels, produced by $\mathrm{CCBs}$, increases the AC activity (and consequently elevating cAMP levels; named as $\mathrm{Ca}^{2+} / \mathrm{cAMP}$ signalling interaction), and these CCBs-effects can be potentiated by cAMP-stimulating compounds (like PDEs inhibitors) and progression, of cancer; for instance, a recent meta-analysis of microarray datasets showed a mRNA gene profile of the L-type $\mathrm{Ca}^{2+}$ channels in different types of cancer [29-34]. For example, it was shown that the L-type $\mathrm{Ca}^{2+}$ channels are significantly up-regulated in colon and esophageal cancer [29-34]. Thus, the pharmacological blockade of these channels could be used as a therapeutic strategy for antitumor therapy. In fact, some studies showed that the L-type CCB, such as amlodipine, mibefradil and NNC-55-0396, inhibited the proliferative response in different tumor cells [6-8].

Furthermore, it was shown that the increase of cAMP, induced by ACs activator, produced significant antitumor effects [9,35]. The 8-ClcAMP, and the PKA -selective cAMP analogs, 8-piperidinoadenosine 3', ''-cyclic monophosphate (8-PIP-cAMP) and 8-hexylaminoadenosine - 3'5'-cyclic monophosphate (8-HA-cAMP), produced significant antiproliferative effects in human cancer cell lines [9,35]. The antiproliferative effect of the PKA -selective cAMP analogs was attributed to a growth arrest, while the 8-Cl-cAMP appears to be due to a pro-apoptotic effect $[9,35]$. These findings suggest that the cAMP analogs, such as 8-Cl-cAMP and the PKA -selective cAMP analogs, could be used in human tumor therapy. Thus, considering that our studies have shown that the reduction of $\mathrm{Ca}^{2+}$ influx through L-type $\mathrm{Ca}^{2+}$ channels, produced by CCBs, increases the AC activity (and consequently elevating cAMP levels; named as $\mathrm{Ca}^{2+} / \mathrm{cAMP}$ signaling interaction) [9-13], and that these CCBs-effects can be potentiated by cAMP-stimulating compounds (like PDEs inhibitors), then the pharmacological modulation of the $\mathrm{Ca}^{2+} / \mathrm{CAMP}$ signaling could be a new therapeutic strategy for the tumor therapy. In addition, our discovery, which demonstrated the role of $\mathrm{Ca}^{2+} / \mathrm{cAMP}$ signaling in the neurotransmitter release and neuroprotection [18-21], may put some new 'light' in the association between hypertension and higher risk for the development of cancer! Moreover, if the dysregulation of the $\mathrm{Ca}^{2+}$ homeostasis may be an issue for the pathogenesis of cancer [9-13]; then, in this scenario, the $\mathrm{Ca}^{2+} / \mathrm{cAMP}$ signaling interaction may be disrupted as a consequence of elevations of $\left[\mathrm{Ca}^{2+}\right] \mathrm{c}$ in the development of cancer process [9-13]. For instance, considering ACs5 and ACs6 isoforms can be inhibited by increases of $\mathrm{Ca}^{2+}$ concentrations [18-25]; then a rise of $\left[\mathrm{Ca}^{2+}\right] \mathrm{c}$ may dramatically disturb the cAMP signaling pathways. Indeed, up-regulations of cAMP signaling have been correlated to anti-cancer effects $[9,13,35]$. Thus, besides its own effect in enhancing the cancer progression, a rise of $\left[\mathrm{Ca}^{2+}\right] \mathrm{c}$ may also probably result in a cancer-excitotoxic effect by reducing anti-cancer responses due to a down-regulation of cAMP signalling pathways (due to a disruption of $\mathrm{Ca}^{2+} / \mathrm{cAMP}$ signaling interaction). In addition, CCBs, as well reducing the influx of $\mathrm{Ca}^{2+}$ into the cells, could exert their anti-cancer effects [6-8] through the $\mathrm{Ca}^{2+} / \mathrm{cAMP}$ signalling interaction. Indeed, novel methodologies will allow researchers, in the future, to explore these hypotheses!

Furthermore, similarly to cancer, hypertension has also been linked to dysregulations of $\mathrm{Ca}^{2+}$ signalling. Miranda, et al. [26-28] discovered definite differences in the kinetics of catecholamine release from spontaneously hypertensive rats (SHRs), comparing with normotensives. Such differences might be explained on the basis of different mechanisms of $\mathrm{Ca}^{2+}$ signalling. Then, in this scenario, the $\mathrm{Ca}^{2+} / \mathrm{cAMP}$ signalling interaction may be disrupted as a consequence of hypertension development process, like in cancer. Thus, similar to cancer, novel methodologies will allow researchers to solve this conundrum!

Then, dysregulations of $\mathrm{Ca}^{2+}$ signalling could provide a 'clinical link' between cancer and hypertension. The following diagram summarizes the previous discussion (Figure 2). 


\section{Dysregulations of $\mathrm{Ca}^{2+}$ homeostasis}

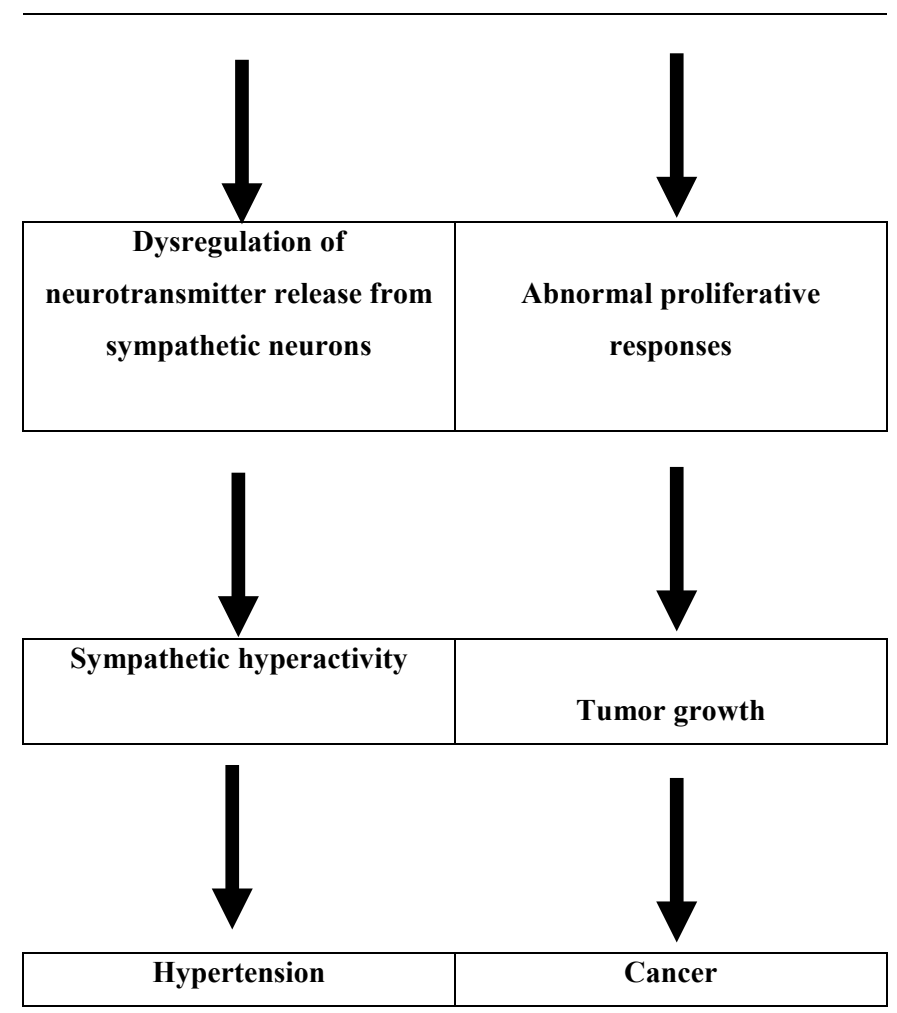

Figure 2. The $\mathrm{Ca}^{2+}$ homeostasis dysregulations and their endpoint consequences: cancer and hypertension

\section{Conclusions and future directions}

$\mathrm{Ca}^{2+}$ signaling and its dysregulations have been implicated in the development of hypertension [26-28] and cancer [29-34]. In addition, CCBs, despite their antihypertensive effect, have been demonstrating anti-cancer effects [6-8]. Furthermore, the $\mathrm{Ca}^{2+} / \mathrm{cAMP}$ signaling interaction has now been emerging as a possible new therapeutic target for treating cancer [9-13]. If the $\mathrm{Ca}^{2+} / \mathrm{cAMP}$ signaling are involved, in part, in the CCBs anti-cancer effects deserves more consideration, including additional experiments with modern methodologies, and in clinical trials.

\section{Conflict of interest}

None declared.

\section{References}

1. Stocks T, Van Hemelrijck M, Manjer J, Bjørge T, Ulmer H, et al. (2012) Blood pressure and risk of cancer incidence and mortality in the Metabolic Syndrome and Cancer Project. Hypertension 59: 802-810. [Crossref]

2. Busselberg D, Florea AM (2017) Targeting intracellular calcium signaling $\left(\left[\mathrm{Ca}^{2+}\right]_{\mathrm{i}}\right)$ to overcome acquired multidrug resistance of cancer cells: A mini-overview. Cancers (Basel) 9: E48. [Crossref]

3. Parkash J, Asotra K (2010) Calcium wave signaling in cancer cells. Life Sci 87: 587595. [Crossref]

4. Monteith GR, Davis FM, Roberts-Thomson SJ (2012) Calcium channels and pumps in cancer: changes and consequences. J Biol Chem 287: 31666-31673. [Crossref]

5. Munaron L, Genova T, Avanzato D, Antoniotti S, Fiorio Pla A (2013) Targeting calcium channels to block tumor vascularization. Recent Pat Anticancer Drug Discov 8: 27-37. [Crossref]
6. Kim KH, Kim D, Park JY, Jung HJ, Cho YH, et al. (2015) NNC 55-0396, a T-type $\mathrm{Ca}^{2+}$ channel inhibitor, inhibits angiogenesis via suppression of hypoxia-inducible factor1alpha signal transduction. J Mol Med 93: 499-509. [Crossref]

7. Yoshida J, Ishibashi T, Nishio M (2007) G1 cell cycle arrest by amlodipine, a dihydropyridine $\mathrm{Ca}^{2+}$ channel blocker, in human epidermoid carcinoma A431 cells. Biochem Pharmacol 73: 943-953. [Crossref]

8. Krouse AJ, Gray L, Macdonald T, McCray J (2015) Repurposing and rescuing of mibefradil, an antihypertensive, for cancer: a case study. Assay Drug Dev Technol 13: 650-653. [Crossref]

9. Bergantin LB (2017) $\mathrm{Ca}^{2+}$ and Camp: Do these Intracellular Messengers 'Work' Independently? Of Course Not, and the History Goes Ahead.... J Clin Exp Oncol 7: 1.

10. Errante PR, Menezes-Rodrigues FS, Leite AA, Caricati-Neto A, Bergantin LB (2017) New antitumoral pharmacological strategies involving $\mathrm{Ca}^{2+} / \mathrm{cAMP}$ signaling pathways. $J$ Cancer Epidem Prev 2: 1-6.

11. Errante PR, Caricati-Neto A, Bergantin LB (2017) Insights for the inhibition of cancer progression: Revisiting $\mathrm{Ca}^{2+}$ and cAMP signaling pathways. Adv Cancer Prev 2: 1-2.

12. Errante PR, Menezes-Rodrigues FS, Caricati-Neto A, Bergantin LB (2017) The pharmacological modulation of $\mathrm{Ca}^{2+} / \mathrm{cAMP}$ intracellular signaling pathways and traditional antitumoral pharmaceuticals: a plausible multitarget combined therapy? $J$ Clin Exper Oncol 6: 1-3. [Crossref]

13. Errante PR, Menezes-Rodrigues FS, Leite AA, Caricati-Neto A, Bergantin LB (2017) The second messengers $\mathrm{Ca}^{2+}$ and cAMP as potential therapeutic targets for the control of cancer progression. Adv Cancer Prev 2: 1-2.

14. Bergantin LB, Souza CF, Ferreira RM, Smaili SS, Jurkiewicz NH, et al. (2013) Novel model for "calcium paradox" in sympathetic transmission of smooth muscles: role of cyclic AMP pathway. Cell Calcium 54: 202-212. [Crossref]

15. Stocks T, Borena W, Strohmaier S, Bjorge T, Manjer J, et al. (2010) Cohort profile: The Metabolic Syndrome and Cancer Project (Me-Can). Int J Epidemiol 39: 660-667. [Crossref]

16. Andreotti G, Boffetta P, Rosenberg PS, Berndt SI, Karami S, et al. (2010) Variants in blood pressure genes and the risk of renal cell carcinoma. Carcinogenesis 31: 614-620. [Crossref]

17. Corrao G, Scotti L, Bagnardi V, Sega R (2007) Hypertension, antihypertensive therapy and renal-cell cancer: a meta-analysis. Curr Drug Saf 2: 125-133. [Crossref]

18. Bergantin LB, Caricati-Neto A (2016) Challenges for the pharmacological treatment of neurological and psychiatric disorders: Implications of the $\mathrm{Ca}^{2+} / \mathrm{cAMP}$ intracellular signalling interaction. Eur J Pharmacol 788: 255-260. [Crossref]

19. Bergantin LB (2017) Neurodegenerative Diseases: Where to Go from Now? Though Provoking Through $\mathrm{Ca}^{2+} / \mathrm{cAMP}$ Signaling Interaction. Brain Disord Ther 6: e125.

20. Bergantin LB (2017) Neurological Disorders: Is There a Horizon? Emerging Ideas from the Interaction between $\mathrm{Ca}^{2+}$ and Camp Signaling Pathways. J Neurol Disord 5: e124.

21. Caricati-Neto A, Garcia AG, Bergantin LB (2015) Pharmacological implications of the $\mathrm{Ca}^{2+} / \mathrm{cAMP}$ signaling interaction: from risk for antihypertensive therapy to potential beneficial for neurological and psychiatric disorders. Pharmacol Res Perspect 3: e00181. [Crossref]

22. Bezprozvanny I, Mattson MP (2008) Neuronal Calcium Mishandling and the Pathogenesis of Alzheimer's Disease. Trends Neurosci 31: 454-463. [Crossref]

23. Caricati-Neto A, Bergantin LB (2017) Pharmacological modulation of neural $\mathrm{Ca}^{2+} /$ camp signaling interaction as therapeutic goal for treatment of Alzheimer's disease. $J$ Syst Integr Neurosci 3: 1-5.

24. Caricati-Neto A, Bergantin LB (2017) The passion of a scientific discovery: the "calcium paradox" due to $\mathrm{Ca}^{2+} /$ camp interaction. J Syst Integr Neurosci 3: 1-5.

25. Caricati-Neto A, Bergantin LB (2017) From a "eureka insight" to a novel potential therapeutic target to treat Parkinson's disease: The $\mathrm{Ca}^{2+} / \mathrm{camp}$ signalling interaction. $J$ Syst Integr Neurosci 4: 1-5.

26. Miranda-Ferreira R, de Pascual R, de Diego AM, Caricati-Neto A, Gandia L, et al (2008) Single-vesicle catecholamine release has greater quantal content and faster kinetics in chromaffin cells from hypertensive, as compared with normotensive, rats. $J$ Pharmacol Exp Therap 324: 685-693.

27. Miranda-Ferreira R, de Pascual R, Caricati-Neto A, Gandia L, Jurkiewicz A, et al (2009) Role of the endoplasmic reticulum and mitochondria on quantal catecholamine release from chromaffin cells of control and hypertensive rats. J Pharmacol Exp Ther 329: 231-240. [Crossref] 
28. Miranda-Ferreira R, de Pascual R, Smaili SS, Caricati-Neto A, Gandia L, et al. (2010) Greater cytosolic and mitochondrial calcium transients in adrenal medullary slices of hypertensive, compared with normotensive rats. Eur J Pharmacol 636: 126-136. [Crossref]

29. Gomez-Ospina N, Tsuruta F, Barreto-Chang O, Hu L, Dolmetsch R (2006) The C terminus of the L-type voltage-gated calcium channel $\mathrm{Ca}(\mathrm{V}) 1.2$ encodes a transcription factor. Cell 127: 591-606. [Crossref]

30. Kale VP, Amin SG, Pandey MK (2015) Targeting ion channels for cancer therapy by repurposing the approved drugs. Biochim Biophys Acta 1848: 2747-2755. [Crossref]

31. Dziegielewska B, Gray LS, Dziegielewski J (2014) T-type calcium channels blockers as new tools in cancer therapies. Pflugers Arch 466: 801-810. [Crossref]
32. Ohkubo T, Yamazaki J (2012) T-type voltage-activated calcium channel Cav3.1, but not Cav3.2, is involved in the inhibition of proliferation and apoptosis in MCF-7 human breast cancer cells. Int J Oncol 41: 267-275. [Crossref]

33. Gackière F, Bidaux G, Delcourt P, Van Coppenolle F, Katsogiannou M, et al. (2008) CaV3.2 T-type calcium channels are involved in calcium-dependent secretion of neuroendocrine prostate cancer cells. J Biol Chem 283: 10162-10173. [Crossref]

34. Latour I, Louw DF, Beedle AM, Hamid J, Sutherland GR, et al. (2004) Expression of T-type calcium channel splice variants in human glioma. Glia 48: 112-119. [Crossref]

35. Murray F, Insel PA (2013) Targeting cAMP in chronic lymphocytic leukemia: A pathway-dependent approach for the treatment of leukemia and lymphoma. Expert Opin Ther Targets 17: 937-949. [Crossref]

Copyright: (C2018 Bergantin LB. This is an open-access article distributed under the terms of the Creative Commons Attribution License, which permits unrestricted use, distribution, and reproduction in any medium, provided the original author and source are credited. 